\title{
A novel "three-port" trocar placement technique for laparoscopic radical prostatectomy
}

\author{
Ben $\mathrm{Xu}^{1 *+}$, Yi-ji Peng ${ }^{1+}$, Guo-zhong $\mathrm{Ma}^{2}$ and Qian Zhang ${ }^{1 *}$
}

\begin{abstract}
Background: To introduce a novel "three-port" trocar placement technique for laparoscopic radical prostatectomy (LRP) in prostate cancer (PCa) patients.

Methods: We retrospectively reviewed 300 patients with PCa who received surgical treatment between November 2010 and June 2015 at our institution. They were divided into group A, three-port LRP; group B, conventional fourfive-port LRP; group C, open RP (ORP); and group D, robotic-assisted RP (RARP). A learning curve was analyzed by dividing patients of group A into the early and late stages.

Results: All groups were comparable with regard to the preoperative characteristics except for the relatively smaller prostate volume in group A. The three-port LRP operations were performed successfully with only 8 cases of conversion to the conventional LRP. None of any severe complications or conversion to ORP occurred. In group A, the mean operative time (OT) duration was 113.8 min, the mean estimated blood loss (EBL) was $94.2 \mathrm{ml}$, the mean drainage days was 4.0 days, the mean hospitalization was 5.1 days, and $27.8 \%$ of the prostate specimen margins (PSM) were positive. The differences of OT, EBL, drainage days, hospitalization, and transfusion in group A were statistically significant among the majority of the other groups $(p<0.05)$. After undergoing the early stages of a learning curve analysis in three-port LRP, the EBL was obviously decreased.
\end{abstract}

Conclusions: Three-port LRP is a novel technique that exhibits superior intraoperative advantages to the conventional LRP. Due to its less OT, EBL, drainage days, hospitalization, and transfusion with a shorter learning curve, it should be recommended and popularized in the clinical practice.

Keywords: Three-port, Trocar, Laparoscopic, Radical prostatectomy

\footnotetext{
* Correspondence: xuben_pku@sina.com; zhangqian@bjmu.edu.cn

${ }^{\dagger}$ Ben $\mathrm{Xu}$ and Yi-ji Peng contributed equally to this work.

'Department of Urology, National Urological Cancer Center, Peking

University First Hospital and Institute of Urology, Peking University, 8 Xishiku

Street, Xicheng District, Beijing 100034, China

Full list of author information is available at the end of the article
}

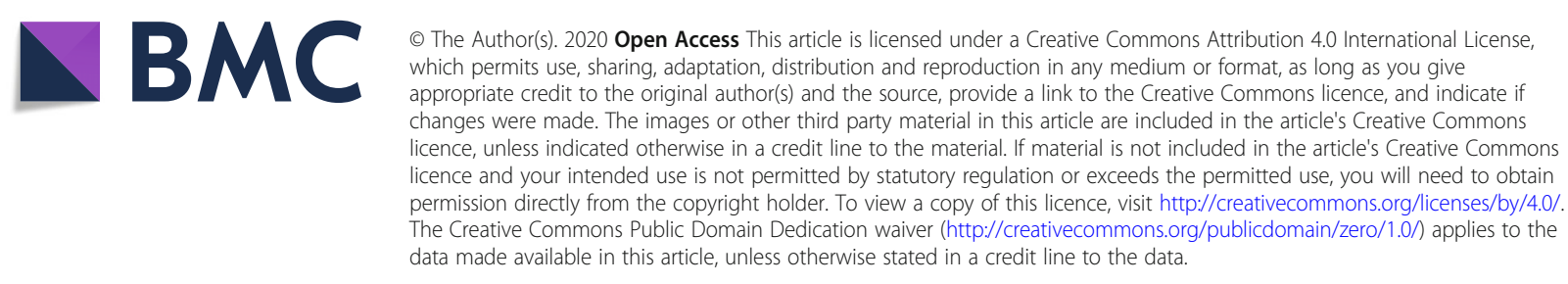




\section{Background}

Prostate cancer (PCa) is the second most common malignant tumor in men and an important cause of cancer-related disease among the patients worldwide [1], accounting for approximately $12 \%$ of newly diagnosed cancer cases in men [2]. In the developed country of the USA, PCa comprises nearly $21 \%$ of newly diagnosed tumors in male patients [3]. The incidence of $\mathrm{PCa}$ in China is much lower than that in western countries but has increased dramatically in recent years [4]. Satisfactory therapeutic effects for $\mathrm{PCa}$ at early stage can be achieved through RP, including ORP, LRP, and RARP $[5,6]$.

RARPs were initially performed in the USA and Germany in 2000 [7], and then, it has gradually surpassed the traditional ORP and been applied extensively as a first-line treatment in several high-volume centers with improved perioperative outcomes without compromising cancer control. Although a high percentage of PCa patients have been treated with RARP, the costs are still too high. This challenge is what many urologic surgeons must face in relatively poor and underdeveloped countries. As a matter of fact, patients undergoing robotic surgery often report dissatisfaction and regret after the operation [8]. Mukherjee et al. [9] and Preisser et al. [10] have also warned that the high total cost of RARP must be kept in mind even though in the USA.

In China, the introduction of robotic systems appears to be sparse compared with that in western countries. The conventional LRP still plays an important role in China, which has the majority of PCa patients among different countries. The situation is also nearly the same in other developing countries [11]. Therefore, the conventional four-five-port LRP might likely continue to exist for many years to come due to its cost. However, the unfamiliar coordination of the surgeon and assistant with a more trocar-associated negative impact on cosmesis both urges us to improve this traditional technique. The three-port LRP is simply a modified technique that we improved, which exhibits superior perioperative advantages when compared with other minimally invasive options. In this investigation, our aim is to assess the safety, feasibility, and advantages of the procedure, which may evolve to be as common as the conventional LRP after continued adaptations. To our knowledge, we are the first to report this novel "three-port" trocar placement technique for LRP.

\section{Methods}

Between November 2010 and June 2015, we retrospectively reviewed the records of PCa patients at our institution. A total of 300 patients receiving the surgical treatment (three-port LRP, the conventional four-fiveport LRP, ORP, and RARP) were selected. Patients who had undergone previous major abdominal surgery, metastatic disease, or radiation therapy were excluded from the trial. These patients were divided into 4 groups based on the detailed surgical approach applied. Group A (three-port LRP) consisted of 144 patients (48.0\%), group B (conventional four-five-port LRP) consisted of 88 patients (29.3\%), group C (ORP) consisted of 57 patients (19.0\%), and group D (RARP) consisted of 11 patients $(3.7 \%)$.

All of the groups were compared according to perioperative parameters, such as age, BMI, prostate volume, prostate serum antigen level, Gleason score, OT, EBL, drainage days, hospitalization days, surgical complications, postoperatively pathological stages, and PSM. The OT was calculated from skin incision to the skin closure. The intraoperative EBL was calculated by anesthesiologists. The complications were recorded according to the Clavien-Dindo grading system. The postoperative pathological tumor stage was established according to TNM 2018. To evaluate the learning speed of the three-port LRP, a learning curve was also analyzed by dividing these 144 consecutive patients into the early stage (72 patients) and late stage (72 patients) according to their surgical periods.

All statistical tests were carried out with the program SPSS v16.0. For statistical analysis, categorical variables were summarized as the frequency and percent. Continuous variables were summarized as the mean \pm standard deviation for normally distributed data. The groups were compared for continuous variables using the independent $t$ test and for proportions using the Pearson chi-square test or Fisher's exact test. The statistical significance level for each hypothesis was established at 0.05 .

All of the patients in group A were performed by an extraperitoneal approach with only three trocars involved by subtracting an additional incision at the McBurney point. A sub-umbilical incision $(1.5 \mathrm{~cm}$ for the prostate volume $\leq 30 \mathrm{ml}$ or $2.5 \mathrm{~cm}$ for the prostate volume $>30 \mathrm{ml}$ ) was initially made through the skin, subcutaneous tissue, and rectoabdominal fascia. Afterwards, a $10-\mathrm{mm}$ trocar was introduced gently through this incision, and the extraperitoneal space was then extended carefully up to the pelvis. Under the direct optic vision through this trocar, the other two incisions for trocar placement were performed successively: one on the right and one on the left lateral margin of the rectus abdominis muscle with a length of 2 finger-breadths below the umbilicus. The operation was performed by only two surgeons (Fig. 1a). The detailed trocar locations are revealed in Fig. 1b, c.

\section{Results}

The detailed patient demographics and outcome characteristics are listed in Table 1 . The groups were comparable 


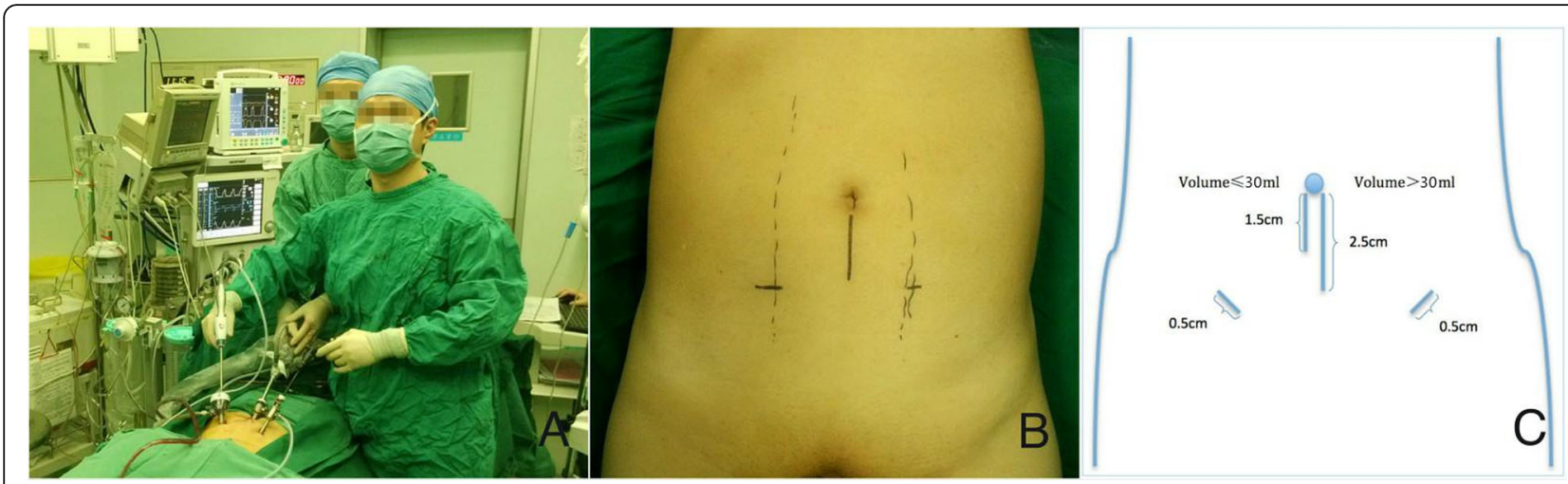

Fig. 1 Images of the external cavity. a With an assistant holding the laparoscope, the surgeon alone completed all procedures of the operation. $\mathbf{b}$ Only three trocars were placed, including one just in the umbilical region and two on the left/right lateral margin of the rectus abdominis muscle with a length of 2 finger-breadths below the umbilicus. c The total lengths of incisions were $1.5+0.5+0.5=2.5 \mathrm{~cm}$ for the prostate volume (evaluated by preoperative B-ultrasonography) $\leq 30 \mathrm{ml}$ or $2.5+0.5+0.5=3.5 \mathrm{~cm}$ for the prostate volume $>30 \mathrm{ml}$

Table 1 Patient demographics and outcome characteristics of patients among groups

\begin{tabular}{|c|c|c|c|c|c|c|c|c|}
\hline \multirow[t]{2}{*}{ Variables } & \multirow[t]{2}{*}{ Group A } & \multirow[t]{2}{*}{ Group B } & \multirow[t]{2}{*}{ Group C } & \multirow[t]{2}{*}{ Group D } & \multirow[t]{2}{*}{$p$ value } & \multicolumn{3}{|c|}{$p$ value after comparison } \\
\hline & & & & & & $A$ vs $B$ & A vs $C$ & A vs $D$ \\
\hline No. patients & 144 & 88 & 57 & 11 & - & - & - & - \\
\hline Age (years) & $66.0 \pm 7.1$ & $67.7 \pm 6.8$ & $66.5 \pm 6.3$ & $68.6 \pm 8.5$ & 0.244 & - & - & - \\
\hline BMI $\left(\mathrm{kg} / \mathrm{m}^{2}\right)$ & $24.2 \pm 2.6$ & $24.8 \pm 2.9$ & $24.6 \pm 2.7$ & $23.6 \pm 2.9$ & 0.253 & - & - & - \\
\hline Smoking history (\%) & $16(11.1 \%)$ & $15(17.0 \%)$ & $6(10.7 \%)$ & $2(18.2 \%)$ & 0.470 & - & - & - \\
\hline ADT history (\%) & $16(11.1 \%)$ & $5(5.7 \%)$ & $1(1.8 \%)$ & $1(9.1 \%)$ & 0.100 & - & - & - \\
\hline PSA level (ng/ml) & $13.4 \pm 12.1$ & $15.2 \pm 12.6$ & $14.1 \pm 27.3$ & $15.2 \pm 17.7$ & 0.867 & - & - & - \\
\hline Prostate volume (ml) & $35.2 \pm 16.0$ & $42.6 \pm 26.7$ & $46.7 \pm 25.2$ & $36.6 \pm 11.5$ & 0.003 & 0.118 & 0.013 & 0.999 \\
\hline \multicolumn{9}{|c|}{ Preoperative Gleason scores by puncture (\%) } \\
\hline$<7$ & $37(25.7 \%)$ & $30(34.1 \%)$ & $20(35.1 \%)$ & $5(45.4 \%)$ & 0.113 & - & - & - \\
\hline$=7$ & $88(61.1 \%)$ & $38(43.2 \%)$ & $28(49.1 \%)$ & $4(36.4 \%)$ & & & & \\
\hline$>7$ & $19(13.2 \%)$ & $20(22.7 \%)$ & $9(15.8 \%)$ & $2(18.2 \%)$ & & & & \\
\hline EBL (ml) & $94.2 \pm 73.4$ & $216.7 \pm 173.2$ & $1247.9 \pm 1137.2$ & $150.0 \pm 130.4$ & $<0.001$ & $<0.001$ & $<0.001$ & 0.661 \\
\hline OT (min) & $113.8 \pm 21.1$ & $130.6 \pm 30.3$ & $240.1 \pm 52.1$ & $214.4 \pm 38.8$ & $<0.001$ & 0.002 & $<0.001$ & $<0.001$ \\
\hline Drainage days (days) & $4.0 \pm 2.6$ & $3.7 \pm 2.9$ & $6.4 \pm 5.7$ & $4.5 \pm 1.6$ & $<0.001$ & 0.973 & 0.018 & 0.913 \\
\hline Hospitalization days (days) & $5.1 \pm 2.9$ & $5.2 \pm 3.4$ & $8.8 \pm 5.8$ & $6.3 \pm 2.5$ & $<0.001$ & 1.000 & $<0.001$ & 0.647 \\
\hline Transfusion (ml) & 0 & $4.5 \pm 42.6$ & $652.6 \pm 789.8$ & 0 & $<0.001$ & 0.897 & $<0.001$ & - \\
\hline \multicolumn{9}{|l|}{ Complications } \\
\hline 0 & $130(96.3 \%)$ & 81 (92.0\%) & $52(91.2 \%)$ & 10 (90.9\%) & 0.104 & - & - & - \\
\hline । & $4(3.0 \%)$ & $5(5.7 \%)$ & $3(5.3 \%)$ & 0 & & & & \\
\hline$\|$ & $1(0.7 \%)$ & 0 & $2(3.5 \%)$ & $1(9.1 \%)$ & & & & \\
\hline III & 0 & $2(2.3 \%)$ & 0 & 0 & & & & \\
\hline \multicolumn{9}{|c|}{ Postoperatively pathological stages (\%) } \\
\hline $\mathrm{T} 2$ & $87(60.4 \%)$ & $41(46.6 \%)$ & $34(59.6 \%)$ & $5(45.5 \%)$ & 0.161 & - & - & - \\
\hline T3 & $57(39.6 \%)$ & $47(53.4 \%)$ & $23(40.4 \%)$ & $6(54.5 \%)$ & & & & \\
\hline PSM (\%) & $40(27.8 \%)$ & $27(30.7 \%)$ & $19(33.3 \%)$ & $4(36.4 \%)$ & 0.792 & - & - & - \\
\hline \multicolumn{9}{|c|}{ Postoperative Gleason scores by operation (\%) } \\
\hline$<7$ & $10(6.9 \%)$ & $9(10.2 \%)$ & $8(14.0 \%)$ & $1(9.1 \%)$ & 0.242 & - & - & - \\
\hline$=7$ & $112(77.8 \%)$ & $56(63.6 \%)$ & $39(68.4 \%)$ & $8(72.7 \%)$ & & & & \\
\hline$>7$ & 22 (15.3\%) & 23 (26.1\%) & 10 (17.6\%) & $2(18.2 \%)$ & & & & \\
\hline
\end{tabular}


with regard to all of the preoperative characteristics except for the relatively smaller prostate volume in group A. The three-port LRP operations were performed successfully with only 8 cases of conversion to the conventional LRP. None of any severe complications or conversion to ORP occurred. Only five mild complications of postoperative ileus and anastomosis leak occurred, but the patient recovered with conservative methods. In group A, the mean OT was $113.8 \mathrm{~min}$, the mean EBL was $94.2 \mathrm{ml}$, the mean drainage day duration was 4.0 days, the mean postoperative hospital stay was 5.1 days, and $27.8 \%$ of the PSMs were positive. The differences of OT, EBL, drainage days, hospitalization, and transfusion in group A were statistically significant among the majority of the other groups ( $p$ $<0.05$ ). However, the other parameters including postoperative complications, postoperative pathological stages, Gleason scores, and PSMs were not significant $(p>0.05)$ among different groups. Above all, group A was associated with a shorter OT, less EBL and blood transfusion, and fewer drainage days and hospitalization.
After undergoing the early stage of a learning curve analysis in three-port LRP, an improvement in the OT, EBL, drainage days, and hospitalization is reflected in Fig. 2. Among them, the EBL was evidently decreased for the initial 72 cases than for the next 72 cases. Although the OT, drainage days, and hospitalization of the initial 72 cases were not significantly different from those of the next 72 cases, a tendency towards more superior outcomes was still observed in the late stage.

\section{Discussion}

Because of the familiar route and reliable touch [12], ORP has always been the "gold standard" treatment for PCa [13], but since 1991, LRP for PCa treatment has been widely disseminated in an attempt to decrease morbidity compared with the traditional ORP [14], even though with high-risk PCa patients [15]. With the improvement of the modern technology and the advent of robotic instruments, RARP was promptly applied in the

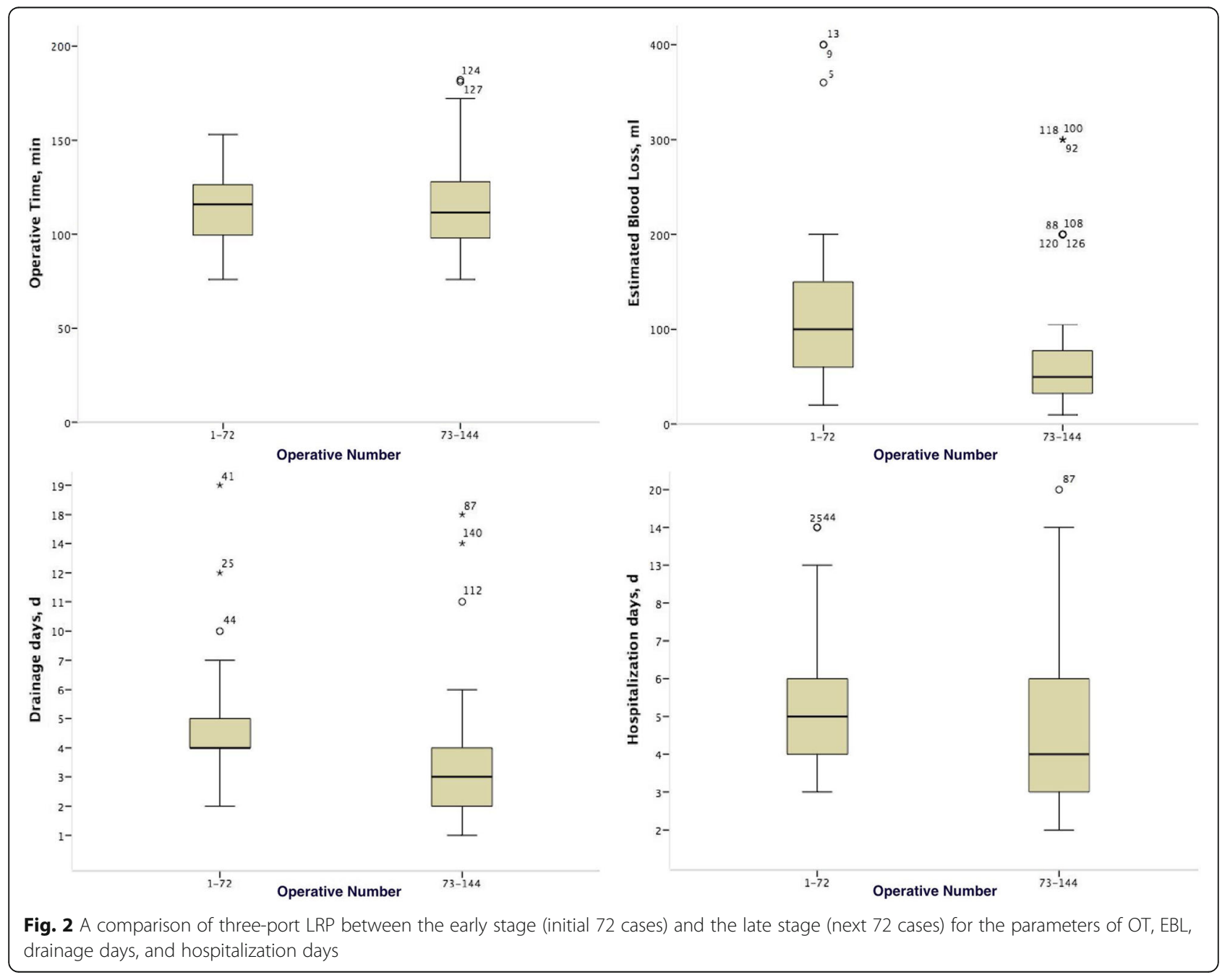


USA and some developed European countries as the most common extirpative treatment for PCa [16].

Nevertheless, the increased technical effort with a longer robot docking time and the increased cost associated with the robot-assisted operation cannot be ignored. It has been demonstrated that over 10 years, RARP was on average more costly than LRP and ORP [17]. Especially in the developing countries such as China, the healthcare resources are in heavy shortage and medical insurance fails to cover the fees on robot-assisted operations. The high cost has also led a number of authorities to question the value of RARP to patients and health care systems. Unfortunately, this unpleasant situation cannot be improved by the surgeons or the hospital itself, but by the economists and politicians. Therefore, the RARP may not be generalizable to the developing countries and community settings. In developing countries such as China, choosing LRP instead of RARP remains common due to the robotic medical expenses that the national health insurance system does not cover. Factually, the standard laparoscopic technique still continues to be practiced in a number of centers due to the higher total hospitalization costs of RARP $[18,19]$.

As for the extensive application of LRP and RARP, it can be further divided into the conventional four-five port and a more minimally invasive single port. Singleport technique is associated with reductions in the number of transcutaneous access points, reducing incision-related complications and improving cosmesis [20], with single-port RARP initially reported in 2019 $[21,22]$. However, due to a loss of triangulation, small operative space and instrument clashes with some doubtful factors on the safety of the procedure and the extended OT, concentrating the incisions at a single site limits the range of motion and makes visualization difficult, which is a huge challenge even for an experienced surgeon. Additionally, the increased cost related to the use of disposable single-port elements must also be taken into account when considering the application of this technique [23].

Du et al. [24] insisted that RARP is more beneficial for PCa patients than LRP and ORP by a system review and meta-analysis. Nevertheless, the extended OT and financial burden of RARP must not be easily neglected. As is well known, prolonged OT is associated with an increased risk of complications in PCa patients [25]. To overcome the above limitations and a loss of triangulation without efficient cooperation by three unfamiliar surgeons of the conventional four-five-port LRP, our team modified the conventional LRP technique and now performs three-port LRP as our first-line treatment for PCa. In our views, three-port LRP combines the advantages of lower cost, faster OT, lower complication rates, and acceptable incision cosmesis. Using laparoscopic vision, the surgeon can detect certain features that cannot be realized accurately and vividly by the RARP.

Table 2 A synopsis of published series on the surgical treatment of PCa

\begin{tabular}{|c|c|c|c|c|c|c|c|c|}
\hline Reference & Treatment & No. of patients & OT (min) & $\mathrm{EBL}(\mathrm{ml})$ & $\begin{array}{l}\text { Drainage } \\
\text { days (days) }\end{array}$ & $\begin{array}{l}\text { Hospitalization } \\
\text { days (days) }\end{array}$ & Complications (\%) & PSM (\%) \\
\hline Zhu et al. [28] & Single-port LRP & 6 & 252.5 & 300 & 11 & NA & 33 & 0 \\
\hline Zhang et al. [29] & Two-port LRP & 15 & 170.1 & 100.7 & 5.7 & NA & 13.3 & 13.3 \\
\hline İnkaya et al. [30] & ORP & 128 & 160 & 1600 & NA & 9 & 81.25 & 33.04 \\
\hline Yaxley et al. [15] & ORP & 151 & 234.34 & 1338.14 & 8.42 & 3.27 & 10.6 & 8.0 \\
\hline İnkaya et al. [30] & Conventional LRP & 48 & 248 & 183 & 11.6 & 3.68 & 8.3 & 12.5 \\
\hline Papachristos et al. [31] & Conventional LRP & 100 & 195 & 300 & NA & 2 & 12 & 13 \\
\hline Sirisopana et al. [32] & Conventional LRP & 241 & 210 & 500 & NA & 6 & 29.05 & 40.63 \\
\hline Johnson et al. [33] & Conventional LRP & 544 & 213 & NA & 10.6 & 3.2 & 19.1 & 27.6 \\
\hline Qi et al. [34] & Conventional LRP & 74 & 143.8 & 316.89 & 4.77 & 7.09 & NA & 45.9 \\
\hline Yaxley et al. [15] & RARP & 157 & 222.03 & 443.74 & 8.21 & 1.55 & 4.5 & 11.0 \\
\hline İnkaya et al. [30] & RARP & 778 & 206 & 172 & 9.2 & 3.02 & 2.4 & 17.0 \\
\hline Papachristos et al. [31] & RARP & 100 & 195 & 300 & NA & 2 & 9 & 10 \\
\hline Sirisopana et al. [32] & RARP & 295 & 200 & 300 & NA & 6 & 8.81 & 39.15 \\
\hline Johnson et al. [33] & RARP & 1081 & 135 & NA & 13.3 & 2.9 & 16.4 & 22.5 \\
\hline Tasci et al. [35] & RARP & 1499 & 181.9 & 225.4 & 2.3 & 2.9 & 6.1 & 14.1 \\
\hline Kaouk et al. [36] & Single-port RARP & 10 & 197.5 & 143 & 8 & 0 & 0 & 50.0 \\
\hline Dobbs et al. [37] & Single-port RARP & 10 & 234 & 65 & 1.3 & 1.3 & 0 & 20.0 \\
\hline Our series & Three-port LRP & 144 & 113.8 & 94.2 & 4.0 & 5.1 & 3.7 & 27.8 \\
\hline
\end{tabular}

PCa prostate cancer, ORP open radical prostatectomy, LRP laparoscopic radical prostatectomy, RARP robotic-assisted radical prostatectomy, No. number, OT operative time, EBL estimated blood loss, PSM prostate surgical margin, NA not available 
Furthermore, the three-port equilateral triangle can avoid a narrow space, which is a remarkable disadvantage when executing a single-port technique. Above all, three-port LRP is the best combination of direct contact with the surgeon's observations, a spacious cavity and efficient coordination in clinical practice. In three-port LRP, the concept of triangulation implies an instrument positioning schema that provides an optimal relationship between the camera and the working instrument. With the bipolar instrument and the laparoscopic traction forceps both in the surgeon's hand, this setup can promote accurate retraction and rapid hemostasis. Some important procedures can be achieved promptly and efficiently only by the surgeon himself. In our clinical practice, three-port LRP is achieved by an extraperitoneal approach instead of a transperitoneal route in view of its lower rate of postoperative complications. Wang et al. [26] and Ragavan et al. [27] have also supported its advantage of extraperitoneal manipulations based on a meta-analysis of LRP and RARP, respectively.

In Table 2, combining our three-port LRP data with other urologists' experience, it can be clearly revealed that our mean OT is significantly shorter. Likewise, the parameters of EBL and the rates of surgical complications are also superior to the other urologists. The perioperative data in our investigation appeared more excellent, which can be explained by three points: (1) a more quick recovery time with less trocar placement and incisions, (2) the risks of faulty operation can be decreased evidently due to the inflexible and excessive traction by an inexperienced and unskilled assistant, and (3) the triangle operation in accordance with the human engineering principle makes the surgeon feel more comfortable and correspondingly reduce the fatigue.

Admittedly, our study has several limitations. This study is retrospective and non-randomized, which clearly biases subsequent analysis. Though the short-term results are encouraging in three-port LRP, the oncological and functional outcomes in the long-term follow-up are still not clear. A series of scientists [38-40] have proposed that there is no evidence to inform the comparative effectiveness of LRP or RARP compared with ORP for oncologic and functional outcomes, which might indicate that three-port LRP can still guarantee an ideal oncologic control balanced with an excellent cosmesis. Hence, further study is still necessary to validate and extrapolate this application.

\section{Conclusions}

By making a comparison between three-port LRP and other surgical techniques, due to its less OT, EBL, drainage days, hospitalization, and transfusion with a shorter learning curve, the novel "three-port" LRP should be recommended and popularized in the clinical practice.

\section{Abbreviations}

LRP: Laparoscopic radical prostatectomy; PCa: Prostate cancer; ORP: Open RP; RARP: Robotic-assisted RP; OT: Operative time; EBL: Estimated blood loss; PSM: Prostate specimen margins; BMI: Body mass index

\section{Acknowledgements}

None

\section{Authors' contributions}

Ben $\mathrm{Xu}$ and $\mathrm{Yi}$-ji Peng carried out the interpretation of data and drafted the manuscript. Guo-zhong Ma participated in the collection of data and data analysis. Qian Zhang assisted in the design of this research and project development. All authors read and approved the final manuscript.

\section{Funding}

None

\section{Availability of data and materials}

N/A

Ethics approval and consent to participate

This experiment was approved by Peking University First Hospital.

Consent for publication

The consent for publication had been obtained from the patients involved.

\section{Competing interests}

None

\section{Author details}

${ }^{1}$ Department of Urology, National Urological Cancer Center, Peking University First Hospital and Institute of Urology, Peking University, 8 Xishiku Street, Xicheng District, Beijing 100034, China. ${ }^{2}$ Department of Urology, Affiliated Hospital of Heze Medical College, 777 Zhujiang Road, Mudan District, Heze City 274000, Shandong, China.

Received: 17 August 2020 Accepted: 15 October 2020

Published online: 27 October 2020

\section{References}

1. Siegel RL, Miller KD, Jemal A. Cancer statistics, 2017. CA Cancer J Clin. 2017; 67:7-30..

2. Mottet N, Bellmunt J, Bolla M, et al. EAU-SETRO-SIOG guidelines on prostate cancer. Part 1: screening, diagnosis, and local treatment with curative intent. Eur Urol. 2017:71:618-29.

3. Miller KD, Siegel RL, Lin CC, et al. Cancer treatment and survivorship statistics, 2016. CA Cancer J Clin. 2016:66:271-89.

4. Wong MC, Goggins WB, Wang HH, et al. Global incidence and mortality for prostate cancer: analysis of temporal patterns and trends in 36 countries. Eur Urol. 2016;70:862-74.

5. Sanda MG, Cadeddu JA, Kirkby E, et al. Clinically localized prostate cancer: AUA/ASTRO/SUO guideline. Part II: recommended approaches and details of specific care options. J Urol. 2018;199:990-7.

6. Stolzenburg JU, Kyriazis I, Fahlenbrach C, et al. National trends and differences in morbidity among surgical approaches for radical prostatectomy in Germany. World J Urol. 2016;34:1515-20.

7. Binder J, Kramer W. Robotically-assisted laparoscopic radical prostatectomy. BJU Int. 2001:87:408-10.

8. Schroeck FR, Krupski TL, Sun L, et al. Satisfaction and regret after open retropubic or robot-assisted laparoscopic radical prostatectomy. Eur Urol. 2008;54:785-93

9. Mukherjee K, Kamal KM. Variation in prostate surgery costs and outcomes in the USA: robot-assisted versus open radical prostatectomy. J Comp Eff Res. 2019;8:143-55.

10. Preisser F, Nazzani S, Mazzone E, et al. Regional differences in total hospital charges between open and robotically assisted radical prostatectomy in the United States. World J Urol. 2019:37:1305-13.

11. Sundram M. Asian robotic experience. Urol Oncol. 2010;28:677-81.

12. van Poppel H, Everaerts W, Tosco L, et al. Open and robotic radical prostatectomy. Asian J Urol. 2019;6:125-8. 
13. Parikh RR, Patel A, Kim S, et al. Comparative effectiveness of laparoscopic versus open prostatectomy for men with low-risk prostate cancer: a matched case-control study. Int J Surg Oncol. 2017;2:e13.

14. Varca V, Benelli A, Perri D, et al. Laparoscopic radical prostatectomy in patients with high-risk prostate cancer: feasibility and safety. Results of a multicentric study. J Endourol. 2018;32:843-51.

15. Yaxley JW, Coughlin GD, Chambers SK, et al. Robot-assisted laparoscopic prostatectomy versus open radical retropubic prostatectomy: early outcomes from a randomized controlled phase 3 study. Lancet. 2016;388: 1057-66.

16. Trinh QD, Sammon J, Sun M, et al. Perioperative outcomes of robot-assisted radical prostatectomy compared with open radical prostatectomy: results from the Nationwide Inpatient Sample. Eur Urol. 2012;61:679-85.

17. Dobbs RW, Magnan BP, Abhyankar N, et al. Cost effectiveness and robotassisted urologic surgery: does it make dollars and sense? Minerva Urol Nefrol. 2017;69:313-23.

18. Basiri A, Rosette JJMCH d I, Tabatabaei S, et al. Comparison of retropubic, laparoscopic and robotic radical prostatectomy: who is the winner? World J Urol. 2018;36:609-21.

19. Ji EY, Na RL, Kwak C, et al. Clinical outcomes and costs of robotic surgery in prostate cancer: a multiinstitutional study in Korea. Prostate Int. 2019;7:19-24.

20. Gettman MT, Box G, Averch T, et al. Consensus statement on natural orifice transluminal endoscopic surgery and single-incision laparoscopic surgery: heralding a new era in urology? Eur Urol. 2008;53:1117-20.

21. Kaouk J, Bertolo R, Eltemamy M, et al. Single-port robot-assisted radical prostatectomy: first clinical experience using the SP surgical system. Urology. 2019;124:309.

22. Kaouk J, Garisto J, Bertolo R. Robotic urologic surgical interventions performed with the single port dedicated platform: first clinical investigation. Eurl Urol. 2019;75:684-91.

23. Schroeck FR, Jacobs BL, Bhayani SB, et al. Cost of new technologies in prostate cancer treatment: systematic review of costs and cost effectiveness of robotic-assisted laparoscopic prostatectomy, intensity-modulated radiotherapy, and proton beam therapy. Eur Urol. 2017;72:712-35.

24. Du Y, Long Q, Guan B, et al. Robot-assisted radical prostatectomy is more beneficial for prostate cancer patients: a system review and meta-analysis. Med Sci Monit. 2018;24:272-87.

25. Simon RM, Howard LE, Moreira DM, et al. Predictors of operative time during radical retropubic prostatectomy and robot-assisted laparoscopic prostatectomy. Int J Urol. 2017;24:618-23.

26. Wang K, Zhuang Q, Xu R, et al. Transperitoneal versus extraperitoneal approach in laparoscopic radical prostatectomy: a meta-analysis. Medicine. 2018;97:e29.

27. Ragavan N, Dholakia kl, Ramesh m, et al. Extraperitoneal vs. transperitoneal robot-assisted laparoscopic radical prostatectomy---analysis of perioperative outcomes, a single surgeon's experience. J Robotic Surg. 2019;13:275-81.

28. Zhu G, Zhang $Y$, Grange $P$, et al. Laparoendoscopic single-site radical prostatectomy: technique and initial outcomes. Chin Med J. 2012;125: 3815-20.

29. Zhang DX, Teng JF, Pan XW, et al. A matched-pair comparison of single plus one port versus standard extraperitoneal laparoscopic radical prostatectomy by a single urologist. Kaohsiung J Med Sci. 2015;31:344-50.

30. Inkaya A, Tahra A, Sobay R, et al. Comparison of surgical, oncological, and functional outcomes of robot-assisted and laparoscopic radical prostatectomy in patients with prostate cancer. Turkish J Urol. 2019;45: 410-7.

31. Papachristos A, Basto M, Marvelde LT, et al. Laparoscopic versus roboticassisted radical prostatectomy: an Australian single-surgeon series. ANZ Surg. 2015;85:154-8.

32. Sirisopana K, Jenjitranant $P$, Sangkum P, et al. Perioperative outcomes of robotic-assisted laparoscopic radical prostatectomy, laparoscopic radical prostatectomy and open radical prostatectomy: 10 years of cases at Ramathibodi Hospital. Transl Androl Urol. 2019;8:467-75.

33. Johnson I, Ottosson F, Diep LM, et al. Switching from laparoscopic radical prostatectomy to robot assisted laparoscopic prostatectomy: comparing oncological outcomes and compliactions. Scand J Urol. 2018;52:116-21.

34. Qi F, Wang S, Xu H, et al. A comparison of perioperative outcome between robot-assisted laparoscopic radical prostatectomy: experience of a single institution. Int Braz J Urol. 2019;45:695-702.

35. Tasci Al, Tufek I, Gumus $\mathrm{E}$, et al. Oncologic results, functional outcomes, and complications rates of robotic-assisted radical prostatectomy: multicenter experience in Turkey including 1499 patients. World J Urol. 2015;33:1095-102.

36. Kaouk J, Valero R, Sawczyn Gl, et al. Extraperitoneal single-port robotassisted radical prostatectomy: initial experience and description of technique. BJU Int. 2020;125:182-9.

37. Dobbs RW, Halgrimson WR, Madueke I, et al. Single-port robot-assisted laparoscopic radical prostatectomy: initial experience and technique with the da Vinci SP platform. BJU Int. 2019;124:1022-7.

38. Ilic D, Evans SM, Allan CA, et al. Laparoscopic and robot-assisted vs open radical prostatectomy for the treatment of localized prostate cancer: a Cochrane systematic review. BJU Int. 2018;121:845-53.

39. Cao L, Yang Z, Qi L, et al. Robot-assisted and laparoscopic vs open radical prostatectomy in clinically localized prostate cancer: perioperative, functional, and oncological outcomes. Medicine. 2019;98:22.

40. Huang $X$, Wang $L$, Zheng $X$, et al. Comparison of perioperative, functional, and oncologic outcomes between standard laparoscopic and roboticassisted radical prostatectomy: a systemic review and meta-analysis. Surg Endosc. 2017:31:1045-60.

\section{Publisher's Note}

Springer Nature remains neutral with regard to jurisdictional claims in published maps and institutional affiliations.
Ready to submit your research? Choose BMC and benefit from:

- fast, convenient online submission

- thorough peer review by experienced researchers in your field

- rapid publication on acceptance

- support for research data, including large and complex data types

- gold Open Access which fosters wider collaboration and increased citations

- maximum visibility for your research: over $100 \mathrm{M}$ website views per year

At $\mathrm{BMC}$, research is always in progress.

Learn more biomedcentral.com/submissions 